\title{
A Bibliometric Research of Social Net- work Theory and Its Applications in MIS Domain
}

\author{
Yili Liu Bing Wu \\ The Economy \& Management School of Tongji University, Shanghai 200092, China
}

\begin{abstract}
An overview of why and how the social network approach might be useful for research of information related issues is presented. Background of social network theory and social network analysis are provided firstly. Then a literature review is made involving a content analysis of 373 articles retrieved from three electronic journal databases offering broad disciplinary coverage with search using two query phrases: social network theory and social network analysis. The review demonstrates the growth of interest and some major trends by MIS and related disciplines in research that applies social network theory and utilizes social network analysis.
\end{abstract}

Keywords: social network theory, social network analysis, management information system

\section{Introduction}

In 1996, researchers realized the applicability of social network analysis to the information profession. Caroline Haythornthwaite made the conclusion that "this approach has practical application in both assessing and modifying information needs and information delivery, providing the information professional with new tools to apply to information issues" [1].With an increased research focus on the social and affective aspects of infor- mation behavior [2] it is valuable to review the contribution that social network theory and analysis make to an understanding of information environment.

To serve this objective, this paper is structured into various sections. Section II provides the background of social network theory and social network analysis. Section III follows with the research method including query phrases and electronic database. Section V demonstrates the research results that reveal the outcome of content analysis. Our recommendations for future research opportunity with SNT and SNA in MIS and related domains are discussed in Section V. At last we draw the conclusion.

\section{Background \& Research Questions}

The difference between social network theory and social network analysis is fundamental. Social network theory seeks to explain the workings of networks, in keeping with definitions of theory as generalizations which seek to explain relationships among phenomena, an internally connected and logically consistent proposition about relationships among phenomena and a complex set of relationships amongst several variables. Social network analysis is the methodology used to research network behavior. Common to both applications are a set of terms and attributes that form the terminology of network research (see Table.1). 


\subsection{Social Network Theory}

Social network theory rooted in the formulation of sociometry and was applied tothe study of groups and group dynamics in the 1930s [3]. Sociometry measures the interpersonal aspects of human relationships, in particular, how people choose each other for different tasks and in different situations [4]. In addition, sociometry advances the observational approach to group dynamics [5] that encourages researchers to measure and observe as ongoing processes. Recent derivatives of sociometry focus primarily on the outcome of the choices made by group members. The true interpretation and value of sociometry is in recognizing that the process of making choices reflects a connection between individuals [6]. Understanding the rationale behind those choices provides a deeper understanding of the interpersonal dynamics of a group. Both outcomes and interpersonal choices are relevant to the behavior of a network.

Social network theory suggests that the patterns and implications of relationships demonstrate specific behavioral principles and properties. The behavior of models that incorporate networks benefits from an understanding of these dimensions. But few network studies utilize theories as the basis for formulating research hypotheses [7]. The use of social network theory as a premise for predicting network behavior is expectedly lower than the application of the methodology to analyze network structure and operations. To date, two prominent network properties provide a framework for viewing network behavior including the strength of weak ties and structural holes [8] [9], and these properties provide the basis for articles invoking the use of social network theory.

\subsection{Social Network Analysis}

\begin{tabular}{|c|c|}
\hline Concept & Description \\
\hline Network & An interconnected system \\
\hline Node/actor/ & $\begin{array}{l}\text { The discrete units in the } \\
\text { network; individual or social } \\
\text { group }\end{array}$ \\
\hline $\begin{array}{l}\text { Network } \\
\text { approach }\end{array}$ & $\begin{array}{l}\text { Level of analysis/discussion of } \\
\text { network relationships }\end{array}$ \\
\hline Egocentric & $\begin{array}{l}\text { Single node as the focus of } \\
\text { attention }\end{array}$ \\
\hline Whole & $\begin{array}{l}\text { Consideration of all nodes in the } \\
\text { environment }\end{array}$ \\
\hline$\cdots \cdots$ & $\cdots \cdots$ \\
\hline
\end{tabular}

Table 1: Terminology of network research.

Social network analysis is an approach and set of techniques applied to the study of the relational aspects of networks. To research the application of concepts of behavior of networks it is essential to identify the roles and positions of the nodes of the network. There are some techniques to capture relational data, including:

- Social network map - an instrument developed by Todd where a series of concentric circles provide the space for an individual to indicate nearness or distance of relatives, friends, neighbors or others in relation to the individual's central position [10].

- Surveys and interviews - personal or group network surveys that identify information exchange connections, or individual interviews that elicit the exchange relations.

- Agent-based technology to capture email and document flow across servers.

- Metrics of journals, authors, citations, co-citations, web sites, online community positions.

Once network data are gathered, a visual representation of the network configuration provides the means to analyze the structural properties. The combination of observation and representation is a cogent approach to enable analysis of group 
process. By mapping the structure of interactions, a researcher can identify the channels through which information flows from one node to another and the potential for a corresponding influence of one over another.

Software modeling is a powerful way to assists the process of data analysis. There are a number of software programs offering the means to input relational data and present visual representations of the resulting network(s). A comprehensive list of software packages is available on the International Network for Social Network Analysis Web site at: www.insna.org/software/software_old.ht $\mathrm{ml}$.

The social network analysis approach applies across disciplines. One is to examine organizational design and structure using a network approach [11]. Another use of social network analysis has been extended in organizations to examine the patterns of relationships across a broad spectrum of opportunities [12]. People can also do research on social networks crediting the availability of patent data to assess links across inventors and organizations and citations in academic articles to study information flows [13]. Applications across other disciplines include counseling research, business logistics and transportation, primary care practices and so on. The application of social network analysis in a number of situations yields valuable understandings of network dynamics.

\subsection{Social Network Analysis}

To guide this study the paper focuses on three research questions:

1. To what extent do management information system (MIS) and related domains and the other disciplines demonstrate interest in social network theory and social network analysis?

2. To what extent do MIS and related domains and the other disciplines demon- strate a growth of interest in social network theory and social network analysis?

3. What are the major focus trends of research studies in social network theory and social network analysis by MIS and related domains?

\section{Research Method}

Content analysis of those articles retrieved from electronic journal databasesElsevier is made. This database provides information on journals in a wide range of academic fields including business, computer science, education, economics, microbiology, genetics, nanotechnology and so on, which offers broad disciplinary coverage for interdisciplinary comparison.

The study content was limited to academic or peer reviewed journals from 2006 to present. We made the search using the query: "social network theory" or "social network analysis". Since this research was designed to examine the application of social network theory and social network analysis, identifying the two phrases as key words or phrases in the title or abstract of an article demonstrates the author's intention to recognize theoretical concepts and methodology.

To select articles in MIS and related domains, the search recognized some journals as the indicator, for example, Expert Systems with Applications, International Journal of Human-Computer Studies, decision support system, industrial marketing management, social networks and futures.

The final data set included 201 feature articles from 95 journals (see Table.2)

\section{Result}

The bibliometric research results, organized in answer to the research questions, reveal the outcome of the content analysis. 


\subsection{Focus in MIS and related do- mains}

The number of articles included in a variety of MIS and related domains journals indicate that MIS and related domains demonstrates interest in social network theory and utilizes social network analysis for their studies (see Table.3).

\begin{tabular}{|l|c|c|}
\hline \multicolumn{1}{|c|}{ Journal } & $\begin{array}{c}\text { Number of } \\
\text { articles }\end{array}$ & percentage \\
\hline $\begin{array}{l}\text { Procedia - Social } \\
\text { and Behavioral } \\
\text { Sciences }\end{array}$ & 12 & 6.0 \\
\hline $\begin{array}{l}\text { Social Science \& } \\
\text { Medicine }\end{array}$ & 11 & 5.5 \\
\hline Social Networks & 10 & 5.0 \\
\hline Animal Behaviour & 7 & 3.5 \\
\hline $\begin{array}{l}\text { Decision Support } \\
\text { Systems }\end{array}$ & 6 & 3.0 \\
\hline $\begin{array}{l}\text { Expert Systems with } \\
\text { Applications }\end{array}$ & 6 & 3.0 \\
\hline Research Policy & 6 & 3.0 \\
\hline $\begin{array}{l}\text { Ecological } \\
\text { Modelling }\end{array}$ & 5 & 2.5 \\
\hline $\begin{array}{l}\text { Preventive } \\
\text { Veterinary Medicine }\end{array}$ & 5 & 2.5 \\
\hline $\begin{array}{l}\text { Computers in } \\
\text { Human Behavior }\end{array}$ & 4 & 2.0 \\
\hline ….. & & 64.2 \\
\hline
\end{tabular}

Table 2: Numbers and percentage of articles per journal.

Of the 39 articles published, the majority (64.1 percent) focused on social network analysis. Decision Support Systems and Expert Systems with Applications published the highest number of articles (30.8 percent) with the nearly fifty-fifty utilizing an application of social network analysis and social network theory. Most journals (92.3 percent) included an article(s) that featured either social network theory or social network analysis while only a few journals (7.7 percent) published articles from both query categories.

Other disciplines also put interest in social network theory and social network analysis. In comparison with the journals of MIS and related domains, journals of social science published more articles focused on social network theory (see Table II). Each of the 201 journal article abstracts was examined for the application of each search phrase.

\begin{tabular}{|c|c|c|c|}
\hline Journal & $\begin{array}{l}\text { Query } \\
\text { SNT } \\
\text { SNA }\end{array}$ & Total & Percentage \\
\hline $\begin{array}{l}\text { Decision Support } \\
\text { Systems }\end{array}$ & $\begin{array}{l}3 \\
3 \\
\end{array}$ & 6 & 15.4 \\
\hline $\begin{array}{l}\text { Expert Systems with } \\
\text { Applications }\end{array}$ & $\begin{array}{l}2 \\
4\end{array}$ & 6 & 15.4 \\
\hline $\begin{array}{l}\text { Computers in } \\
\text { Human Behavior }\end{array}$ & $\begin{array}{l}2 \\
2 \\
\end{array}$ & 4 & 10.3 \\
\hline $\begin{array}{l}\text { Information } \\
\text { Processing \& } \\
\text { Management }\end{array}$ & $\begin{array}{l}1 \\
3\end{array}$ & 4 & 10.3 \\
\hline $\begin{array}{l}\text { Computers \& } \\
\text { Education }\end{array}$ & $\begin{array}{l}1 \\
2\end{array}$ & 3 & 7.7 \\
\hline $\begin{array}{l}\text { Journal of } \\
\text { Informetrics }\end{array}$ & $\begin{array}{l}1 \\
2 \\
\end{array}$ & 3 & 7.7 \\
\hline $\begin{array}{l}\text { Information and } \\
\text { Software } \\
\text { Technology }\end{array}$ & 2 & 2 & 5.1 \\
\hline $\begin{array}{l}\text { Theoretical } \\
\text { Computer Science }\end{array}$ & $\begin{array}{l}1 \\
1\end{array}$ & 2 & 5.1 \\
\hline $\begin{array}{l}\text { Computational } \\
\text { Statistics \& Data } \\
\text { Analysis }\end{array}$ & 1 & 1 & 2.6 \\
\hline $\begin{array}{l}\text { Computer } \\
\text { Communications }\end{array}$ & 1 & 1 & 2.6 \\
\hline $\begin{array}{l}\text { Data \& Knowledge } \\
\text { Engineering }\end{array}$ & 1 & 1 & 2.6 \\
\hline Information Systems & 1 & 1 & 2.6 \\
\hline $\begin{array}{l}\text { Knowledge-Based } \\
\text { Systems }\end{array}$ & 1 & 1 & 2.6 \\
\hline $\begin{array}{l}\text { Library \& } \\
\text { Information Science } \\
\text { Research }\end{array}$ & 1 & 1 & 2.6 \\
\hline $\begin{array}{l}\text { Mathematical and } \\
\text { Computer } \\
\text { Modelling }\end{array}$ & 1 & 1 & 2.6 \\
\hline $\begin{array}{l}\text { The Journal of } \\
\text { China Universities } \\
\text { of Posts and } \\
\text { Telecommunications }\end{array}$ & 1 & 1 & 2.6 \\
\hline $\begin{array}{l}\text { Web Semantics: } \\
\text { Science, Services } \\
\text { and Agents on the } \\
\text { World Wide Web }\end{array}$ & 1 & 1 & 2.6 \\
\hline totoal & $\begin{array}{l}14 \\
25\end{array}$ & 39 & 100 \\
\hline
\end{tabular}

NOTE: SNT=Social Network Theory SNA $=$ Social Network Analysis

Table.3: Numbers of articles per journal of MIS and related domains 


\subsection{Growth of interest in social net- work theory and social network analysis}

The increase in articles published over the five years indicates a growth of interest in social network theory and social network analysis (see Figure.1). The trend intensifies post-2006. While the use of social network theory increased in the past five years, the application of social network analysis more than triples. The use of methodology consistently outweighs the application of theory in articles published since 2006 .

MIS and related domains demonstrate the same trend as other disciplines in terms of increasing interest in social network theory and social network analysis (see Figure.2).

However, the extent of MIS and related domains interest draw more concentrations with SNT and SNA than most other disciplines in the period. As with other disciplines, the use of methodology consistently outweighs the application of theory.

\section{FREQUENCY}

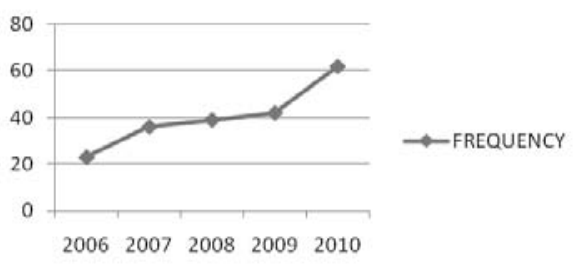

Fig. 1: Frequency of article publication for all disciplines since 2006.

\subsection{Common features of the re- searches with SNT\&SNA}

The paper details the research of a variety of relational dynamics and efforts to make a deep understanding of the formation and behavior of social networks. Each article identified a primary location, for example, organizational settings, edu- cation settings, medical facilities, for the study or discussion.MIS and related domains situated the highest percentage of its studies in the online environment.

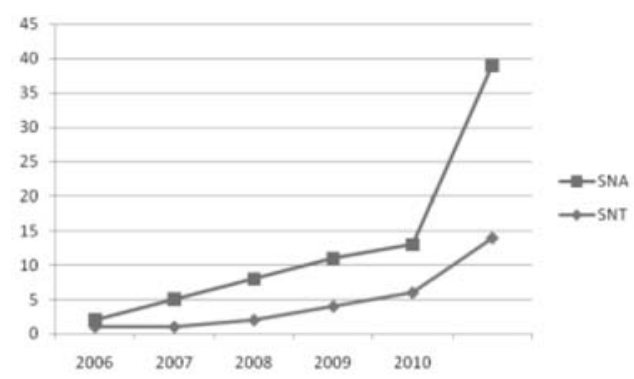

Fig. 2: Frequency of article publication for MIS and related domains since 2006.

There are three types of the research streams from this review. First, a number of studies ( 40.5 percent) focused on the impact or value received from a network situation. These studies examined network structures, the different roles that different actors assumed, and the return on these network connections. The research studies focused on understanding the interactions between actors and expressed value as social capital, power, trust, economic advantage, support, and development potential.

Secondly, a number of studies (30.1 percent) focused on the activation of a network to diffuse or disseminate information or resources. The diffusion study includes the movement of knowledge, information, language, disease, addictive habits and affective behaviors.

Thirdly, a number of studies (24.3 percent) emphasized influence relating to the impact an individual unit has over another. These studies included collaborative ventures, strategic alliances, citation analyses, mentor associations and coalitions. Articles in MIS and related domains demonstrated an interest in intellectual and social influence through citation analysis, cocitation analysis or hyperlink affiliations. 
Finally, a small group of studies (5.1 percent) concentrated solely on the efforts of individuals or firms seeking specific information on a topic or theme.

\section{Discussion}

The study demonstrates an increasing and continuing interest in social network theory and social network analysis by MIS and other disciplines. Three observations are given as following.

Firstly, the study demonstrates the movement of applications of SNT and SNA. Networks is viewed form solely as "a system of objects (e.g. people, groups, organizations) joined by a variety of relationships" [14], toward "more relational, contextual and systemic understandings" [15]. In MIS field researches move from primary emphasis on understanding the structure of networks to understanding the information environment within which networks reside and the information environment that is created by a network structure and function, which places the research of networks alongside information behavior in context.

Secondly, the researchers' interest are in explaining network behaviors, both from the perspective of an individual actor (egocentric) or a complete (whole) network of contacts. There are two dominant network properties provided the impetus for many studies citing social network theory identified by Granovetter and Burt. Granovetter's strength of weak ties often extrapolates to information seeking behavior and Burt's observations of structural holes yields opportunities (entrepreneurial, social capital) or missteps from gaps in a network's structure.

Finally, in MIS and related domains social network theory provides an avenue to explore information behavior and build an understanding of the nature of information exchanges. SNA also can be applied in association with additional theo- ries as they sought to explain or reveal the information behavior of social interactions: small world theory, social capital and role theory. The valuable research direction is to apply SNA with online settings, such as e-commerce, e-learning, etraining, social networking service.

\section{Conclusion}

As Barbara Schultz-Jones pointed [9], SNA can be used for following research applications. These include:

- the role of the librarian or library as gatekeeper within an information network structure;

- the ways in which structural changes affect an information network over time;

o examining information behavior how information access contributes to network development;

$\circ$ the ways in which network positions and structures facilitate or restrict information delivery;

- analyzing networks to maximize the range of connections and likelihood of receiving different kinds of information;

- analyzing the structural dimensions of networks to include the introduction of information and communication technologies (ICTs); and

$\circ \quad$ investigating computermediated communication and information systems.

The growth of research literature devoted to applications of social network theory and analysis suggests that there is value in this approach. The derived value extends to an understanding of how information exchanges facilitate the delivery of services. With continued research on information behaviors in context, the 
possibilities for developing additional concepts of social network theory exist. Using social network analysis in MIS and related domains could advance valuable contributions to an understanding of existing information behavior, especially the development of social networking service.

\section{References}

[1] Haythornthwaite, C. (1996), "Social network analysis: an approach and techniques for the study of information exchange", Library \& Information Science Research, Vol. 18 No. 4, pp. 323-42.

[2] Otte, E. and Rousseau, R. (2002), "Social network analysis: a powerful strategy, also for the information sciences", Journal of Information Science, Vol. 28 No. 6, pp. 441-53.

[3] Moreno, J.L. (1934), Who Shall Survive?, Beacon Press, New York, NY.

[4] Blumberg, H.H. and Hare, A.P. (1999), "Sociometry applied to organizational analysis: a review", Action Methods, Vol. 52 No. 1, pp. 15-37.

[5] Moreno, J.L. (1954), "Old and new trends in sociometry: turning points in small group research", Sociometry, Vol. 17 No. 2, pp. 179-93.

[6] Remer, R. (1995), "Strong sociometry: a definition", Journal of Group Psychotherapy, Psychodrama \& Sociometry, Vol. 48 No. 2, pp. 69-75.

[7] Monge, P.R. and Contractor, N.S. (2003), Theories of Communication Networks, Oxford University Press, New York, NY.

[8] Granovetter, M.S. (1983), "The strength of weak ties: a network theory revisited", Sociological Theory, Vol. 1, pp. 201-33.

[9] Barbara Schultz-Jones, Examining information behavior through social networks -An interdisciplinary review,
Journal of Documentation, Vol. 65 No. 4, 2009, pp. 592-631

[10] Hersberger, J. (2003), “A qualitative approach to examining information transfer via social networks among homeless populations", The New Review of Information Behavior Research, Vol. 4 No. 1, pp. 95-108.

[11] Tichy, N.M., Tushman, M.L. and Fombrun, C. (1979), "Social network analysis for organizations", The Academy of Management Review, Vol. 4 No. 4, pp. 507-19.

[12] Borgatti, S.P. and Foster, P.C. (2003), "The network paradigm in organizational research: a review and typology", Journal of Management, Vol. 29 No. 6, pp. 991-1013.

[13] Sorenson, O. and Waguespack, D.M. (2005), "Research on special networks and the organization of research and development: an introductory essay", Journal of Engineering and Technology Management, Vol. 22 Nos $1 \& 2$, pp. 1-7

[14] Tichy, N.M., Tushman, M.L. and Fombrun, C. (1979), "Social network analysis for organizations", The Academy of Management Review, Vol. 4 No. 4, pp. 507-19.

[15]Borgatti, S.P. and Foster, P.C. (2003), "The network paradigm in organizational research: a review and typology", Journal of Management, Vol. 29 No. 6, pp. 991-1013. 